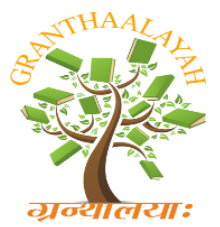

INTERNATIONAL JOURNAL OF RESEARCH GRANTHAALAYAH A knowledge Repository

\title{
SOCIO-ECONOMIC AND ECOLOGICAL IMPACT OF MALARIA - A CASE STUDY OF NEEMUCH, MADHYA PRADESH
}

\author{
Sadhana Sewak \\ Govt. Girls College, Neemuch (M.P)
}

\begin{abstract}
Malaria is one of the oldest chronic, most dreaded killer diseases. It is a protozoan Plasmodium borne disease which is transmitted in humans by very efficient mosquito Anopheles. Out of four plasmodium genus, vivax is more dominant and falciparum species likely to cause severe lethal malaria. According to WHO, malaria killed 627000 people in 2012, majority of them sub-Saharan African children under the age of 5. This preeminent tropical parasite disease is one of the top 3 killers among communicable diseases. It is the only vector borne disease to be placed on WHODALY's (disability adjusted life years) list, as it affects the mortality and morbidity rate as well as economy of any country.

Keywords:

Malaria, diseases, socio-economic, ecological impact.

INTRODUCTION

India contributes about $70 \%$ of malaria in South East Asian region of WHO. According to world malaria report 2014, India's 22\% population lives in high transmittance area. In 2013, .88 million cases has been recorded. In India there are 6 recognized vectors of malaria. A-culicifalicies is the vector of rural malaria; A.stephenicii is reported as vector of urban malaria.

Malaria has a huge burden on society and health services. Its socioeconomic aspects are studied well. There is a need to understand this biomedical problem as socio cultural as well as ecological burden. Factors affecting social burden are, costs of individual and families to buy drugs, expenses to travel to clinics for treatment, lack of awareness regarding the causes, prevention and its control, absence from school and work place and expenses for its prevention etc. Cost affecting Government are, supply of medicines and maintenance of staff and medical services.
\end{abstract}

\begin{abstract}
AIM
Aim of the present study is to enrich understanding of malaria in rural and urban areas of Neemuch and to correlate its socio economic and ecological perspective as a burden.
\end{abstract}

\section{METHODOLOGY}

Neemuch is a small district of western M.P., lying at the border touching Chittorgarh and Pratapgarh districts of Rajasthan. Studies were carried out in three villages of three blocks of Neemuch to cover rural malaria and in Neemuch block to study urban area. Data collection was done by specially designed household surveys with the help of questionnaire and interviews. About 
200 random households have been sampled to find socioeconomic as well as ecological aspects Data from malaria control department of District Hospital in Neemuch were analysed. Questions to find out there social status, economics status, habits of cleanliness, treatment mode, decision power in family, knowledge of symptoms, causes and mode of prevention were asked. The awareness level about the facilities provided by the government for the treatment and control measures were also asked. To find its relationship with ecological and environmental changes, questions were included to find the level of awareness about its impact on health.

\section{RESULTS AND DISCUSSION}

Poverty, lack of awareness, illiteracy, and gender discrimination were main factors came out strongly in data analysis of the random survey. No" cultural", "social" or" traditional" practice to cure was found .Lack of knowledge and awareness about causative agent mosquitoes, its prevention or control is one of the reasons not to control this epidemic. Inadequate medical services with less staff and medicines are the social factors came out on part of Government. In local language, it is known as "Ekatra" (The fever occurring after 48hours, every alternate day due to P.Vivax)) People in villages still go to temples and choukis for "Jhada" and "Mantar. Females of rural area still depend on their male members for the treatment decisions, which delay the treatment and extent of treatment. People depend on Panchayats and Nagarpalika for cleanliness. Action is not taken by authorities to control malaria, such as timely spread of insecticides, timely slide tests, distribution of medicated mosquito nets, or medicines. So, the cost of drugs and visits to doctors is unbearable, delays the treatment, thus pose socio-economic burden on society. No educational "campaigns" or awareness camps are organized. Living status has straight relationship with habits of cleanliness. People live with their animals, storage of rain water in puddles, naalis provide place for breeding of mosquitoes. They don't use insecticides or mosquito killers. Although under National Vector Borne Disease Control Program, Asha Karyakarta and paramedical staff have been appointed by the government for control of the disease, and the data of malaria department shows decreased rate of cases of malaria. People are not aware of any of these programs. Absence from schools and workplaces is a common practice, causing economic loss to society and the nation. Profession did not come out as a key factor. People doing hard physical labour (villagers) and leading urban life, both are affected equally.

In urban area of Neemuch, people go to hospitals in the cases of fever. Results states that malaria occurrence was $80 \%$ in lower, $64 \%$ in lower middle income group and 58\% in higher income groups. Most of the difference is related to the environment lying inside and outside their houses such as sanitation facilities, poor drainage system, open blocked drains, poor sullage system. Water logging, indoor water storage in open containers provide suitable habitat for mosquito breeding. The data from the Malaria Department shows in urban Neemuch, only $10-11 \%$ of the total registered fever cases were the cases of malaria. Results of slide tests were positive for vivax. Falciparum malaria was not found and no deaths have been registered in the district due to malaria. This difference may be related to the education level and awareness about the treatment mode adapted by the urban people. The main cause of urban malaria, which came as a strong ecological reason is, increased the urbanization due to deforestation and changed agricultural land use patterns. Construction of cemented roads, formation of new water structures such as dams, canals for human settlements influence the vectoral capacity, provide new breeding places to mosquitoes. The vacant plots of the city are trenching grounds. The solid wastes and rainwater of the plots and holes of roads has become the problem, posing impact on human health, have helped in the well growth of Parthenium- The Congress grass and breeding place for mosquitoes. Nagar-Palika and 
Health department are careless about the arrangements for drainage system and cleanliness. Spread of insecticides and fumigation drives are not a regular part of disease control program. People do not take any preventive measures; expect authorities or government for control measures. People of rural as well as urban area have no knowledge of its association with climate changes. People migrated from villages to urban areas, live in unhealthy slums, lack minimum health care facilities is an important urban social factor.

\section{CONCLUSION}

A sound local understanding of preventive measures and health seeking behavior is important for effective control of malaria. To combat its spread, access to proper health treatment at community level is essential. Severity of malaria leads to poor health outcomes which in turn lead to a low gross national income and economic growth.

An environmental change, whether occurring as natural phenomena or through human interventions, alters the ecological balance. The unfamiliar climate changes, deforestation and irregular rainfall affects life cycle of vector, pose impact on spread of diseases. Abiotic elements, rise in temperature, precipitation, humidity affects the abundance of mosquitoes and vector. Biotic factors operating through deforestation, changed agricultural practices pose influence on vectoral capacity, allows more sunlight on floor, affects $\mathrm{pH}$ of soil and water, favours mosquito breeding, especially Anopheles larvae development.

Thus, besides socio-economic burden, environmental changes have become the lead cause of malaria. Drug resistant, Insecticide resistant mosquitoes, due to genetic mutation are also a barrier to prevent malaria. The ratio of Medical staff and affected patients is a major issue. There is a strong need to adopt strategies to reduce malaria and improve the quality of life and productivity and lessen the medical burden.

National Malaria Control program and National Vector Borne Diseases Control Program has been implemented to defeat malaria to zero status, with the help of WHO. To sensitize people, a multidimensional approach is required. Besides accurate and consistent diagnosis and treatment, provision and supply of effective drugs up to full cure is must to save from unnecessary cost burden, Most agreed solution is to organize mass campaign for education and train them to prevent it. Use of mosquito nets, insecticides, clean premises with proper drainage will help community lives.

To combat the consequences of the climate change, by recognizing ecological imbalances, timely action taken and committed efforts by Government and local residents is needed to eradicate malaria. By developing new tools and plan public health interventions, this burden can be reduced.

\section{REFERENCES}

1. Dhiman R C; Sharma S K; Pillai C R: and Subbarao S K; 2001; "Investigation of Outbreak of Malaria in Tribal Area of Vishakhapatnam (AndhraPradesh)"; Current - Science 80 (c), 781-785.

2. Esse C, Utizinger J; Tschanneur AB; Raso G; "Social and Cultural Aspects of Malaria and its Control".

3. Mitra AP; Bhattacharya Sumana; Dhiman RC; Krishnakumar K; Sharma C; "Impact on Climate Change on Health: A Case Study of Malaria in India".

4. Pattanayak Shubhendu ; Dickinson Kathereine; "Deforestation,Malaria and Poverty - A Call for Transdisciplinary Research to Support the Design of Cross Sectoral Policies". 
[Social Issues and Environmental Problems, Vol.3 (Iss.9:SE): Sep, 2015] ISSN- 2350-0530(O) ISSN- 2394-3629(P)

Impact Factor: 2.035 (I2OR)

5. Singh Abhalakshmi; Rahman Atiqur; "Malaria and Related Environmental Issues in India; A Case Study of Aligarh”. 2001 Geojournal 89: 89-99.

6. www.malariasite.com/malaria/malariain India 